\title{
Metanephric Adenoma of the Kidney: A Case Report and Literature Review
}

\author{
Muhammad Asykar Palinrungi ${ }^{1}$, Prihantono Prihantono ${ }^{2, *}$ \\ ${ }^{1}$ Department of Surgery, Faculty of Medicine, Chairman of Urology Division, Hasanuddin University, Makassar, Indonesia \\ ${ }^{2}$ Department of Surgery, Faculty of Medicine, Hasanuddin University, Makassar, Indonesia \\ *Corresponding author: prihantono.md@gmail.com
}

\begin{abstract}
Metanephric Adenoma is a rare benign renal epithelial tumor, only a few reports are found in the literature. Reported a 48-year-old female with a palpable mass at left flank, pain and microscopic haematuria. Radiological imaging shows a mass on left Kidney suspected of Renal Cell Carcinoma. Transperitoneal left radical nephrectomy was done. Histopathological results revealed a Metanephric adenoma. The patient is repatriated from the hospital four days after surgery. The patient is in good health, and there is no sign of recurrence on 48 months follow up after surgery.
\end{abstract}

Keywords: renal tumor, radical nephrectomy, metanephric adenoma

Cite This Article: Muhammad Asykar Palinrungi, and Prihantono Prihantono, "Metanephric Adenoma of the Kidney: A Case Report and Literature Review.” American Journal of Medical Case Reports, vol. 5, no. 9 (2017): 244-247. doi: 10.12691/ajmcr-5-9-5.

\section{Introduction}

Metanephric Adenomas referred to as "nephrogenic adenoma" or "embryonal adenoma," is a rare benign tumor, which clinically, clinical immunohistochemically and tumor histology of this tumor are unique [1,2,3]. Metanephric Adenoma was first described in 1979 by Bove et al. [1]. Pages and Granier proposed the term nephrogenic nephroma in 1980 [3], regarded as adenomas by Mostofi et al. in 1988 [4]. This type of tumor is only $0.2 \%$ of the Renal epithelial neoplasms [5], and so far less than 200 cases were documented in the world literature [6]. According to the theory, these tumors are derived from the primitive metanephric epithelium of the proximal nephron remainings. Histologically, these tumors are associated with Wilms' tumor and another nephrogenic tumor; even it can be found simultaneously $[1,2,4,7]$.

Metanephric Adenoma usually appears in middle-aged women [5,8], but it is also found in children $[9,10,11]$. Usually, these types of tumors are asymptomatic and discovered incidentally when dealing with other diseases. Symptoms that may arise are in the form of mass in the abdomen, flank pain, microscopic hematuria, hypertension and fever [1-9]. Approximately 12\% cases of Metanephric adenoma arise in paraneoplastic syndrome such as polycythemia and hypercalcemia [5,6,7]. Based on radiological and morphological findings, this tumor is solid, wellcircumscribed with calcifications and hypovascularity. Clinically and diagnostically, it is essential to distinguish this tumor with other nephrogenic tumors (nodular renal blastema, epithelial Wilms' tumor and Papillary Renal Carcinoma). Knowledge of metanephric adenoma is essential in its management, in which resection has been proven effective in most cases $[4,8,9]$.

\section{Case Report}

A 48-year-old woman came with chief complaint of palpable mass at the left flank sized as a tennis ball, accompanied by intermittent pain since 5 months ago without complaining hematuria. Physical examination revealed a mass in the left flank region sized $6 \mathrm{~cm} \times 6 \mathrm{~cm} \mathrm{x}$ $5 \mathrm{~cm}$, hard in consistency, with irregular surfaces and no tenderness. Laboratory findings are within normal limits, microscopic hematuria was found on urinalysis examination. A solid mass was seen in abdominal ultrasound sized $70 \mathrm{~mm}$ x $63 \mathrm{~mm}$ x $65 \mathrm{~mm}$ on lower pole of left kidney without dilatation of pelviocalyceal system and no metastases in other organs. CT urography revealed obvious mass sized $72 \times 93 \times 70 \mathrm{~mm}$ at the lower pole of the left kidney. Enhanced contrast CT-scan of the left kidney and right kidney are within normal limits (Figure 1). Chest $\mathrm{X}$-ray resulted in no sign of metastatis.

The patient was diagnosed with left kidney tumor suspected Renal Cell Carcinoma T2NoMo, Karnofsky scores $90 \%$. Transperitoneal left radical nephrectomy was performed, and the histopathological examination revealed nests of a tumor with a clear boundary, small ducts and tubules covered by epithelial cells, slightly larger nuclei than lymphocytes, irregular round-shaped, ovoid, smooth chromatin, overlapping with little cytoplasm and the basement membrane was intact. Prominent few tubules with papillary formations were seen, no mitosis was found (Figure 2). The diagnosis of metanephric adenoma was then made. 


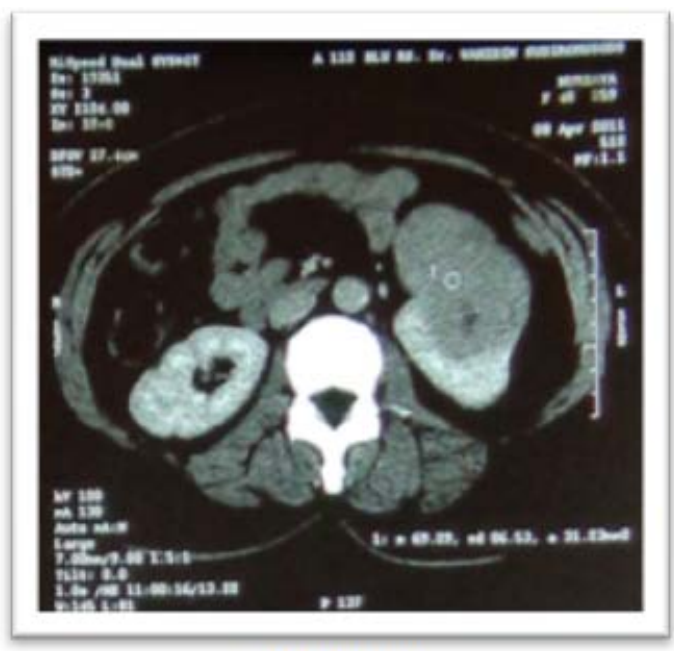

Axial view

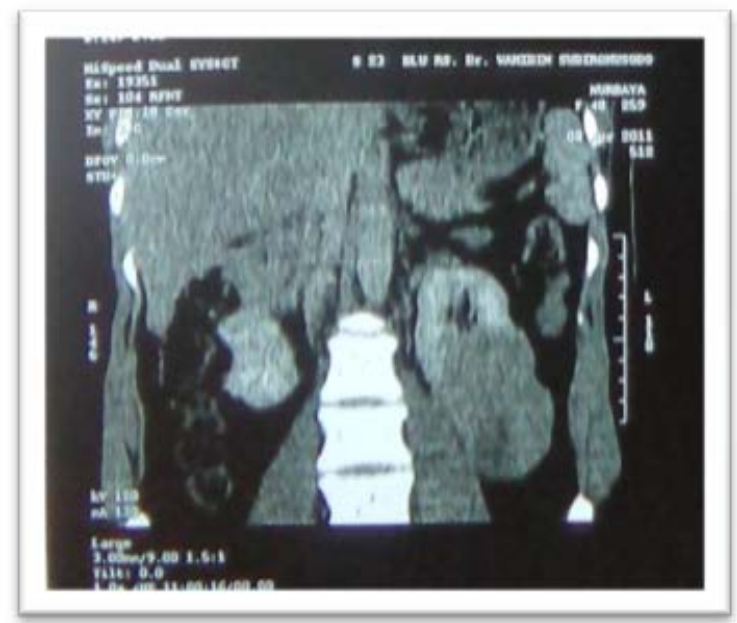

Coronal view

Figure 1. Enhanced contrast CT-scan of the left kidney

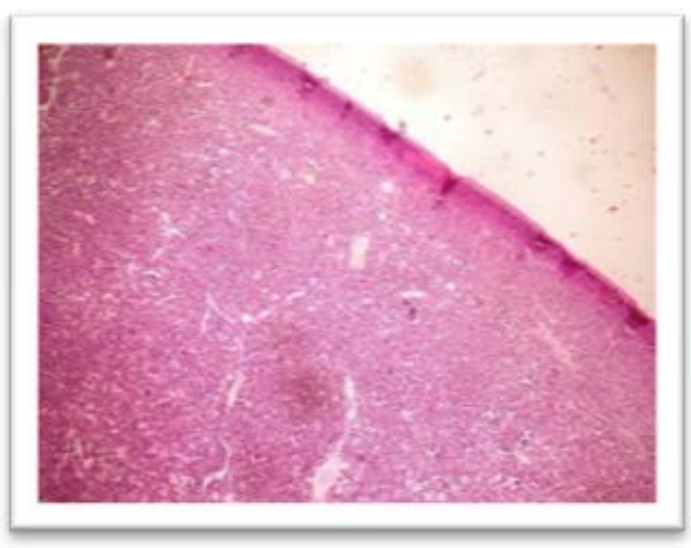

4x Enlargement

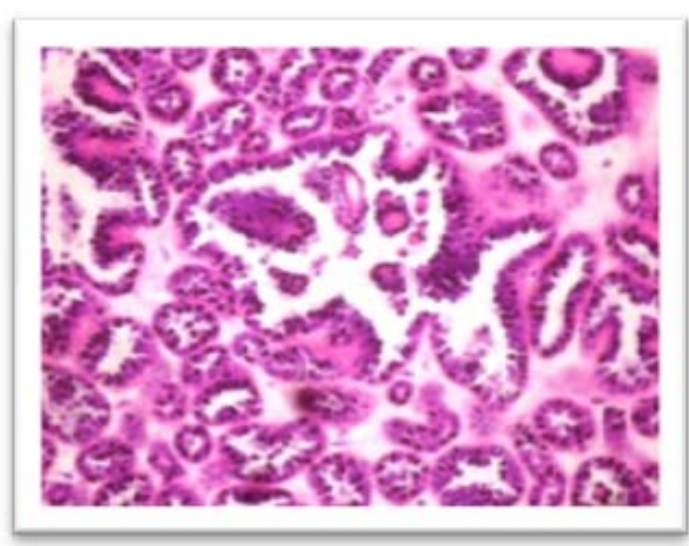

40x Enlargement

Figure 2. Metanephric adenoma cells with different enlargement

\section{Discussion}

In the embryonic phase, the kidney was developed from metanephric blastema [8]. If there is still tissue left in renal parenchyma after birth, the tissue is then likely to evolve into Wilms' tumor or sometimes develop into Metanephric adenoma. According to the theory, these tumors are derived from the primitive metanephric epithelium of the proximal nephron remainings. Therefore, Wilms' tumor and metanephric adenoma are still considered to have a hystogenetic similarity, sometimes metanephric Adenoma is considered as a benign type of Wilms' tumors in adults [1,2].

Metanephric adenoma was initially found by Boye et al. in 1979 from a 7-year-old boy, and it was believed to develop from primitive epithelium which failed on maturation process of proximal tubule of kidney [12]. In 1980, Page and Granier suggested the name "Nephrogenic Nephroma" for these tumors [12]. Since then, approximately 130 cases have been reported in the world literature. In 1995, based on 22 years' data obtained from the Armed Forces Institute of Pathology, Washington DC, as many as 50 cases of metanephric adenoma were published by Davis et al [13]. This study includes 36 females and 14 males (F: $M=2,6: 1$ ) with histologic results of metanephric adenoma. The patients were varied in age from 5 to 83 years. Metanephric adenoma cases were coincidentally found in 20 patients $(40 \%)$, and six patients had polycythemia (12\%). 11 patients (22\%) presented with abdominal pain/flank pain, 5 with hematuria $(10 \%)$ and another 5 with abdominal mass (10\%). Preoperative radiological examination of this tumor showed calcification in $44 \%$ cases. Based on the distribution of cases by sex and age, most Metanephric adenoma occurs in young adult and a middle-aged woman, but there are also reported cases in children and adults [13].

Liniger et al. reported metanephric adenoma case in a 15-month-old boy, claimed as the youngest case ever reported. Looser et al. also reported a case of a 2-year-old girl with metanephric adenoma of left renal [14].

Metanephric adenoma is commonly found accidentally during an examination for other diseases, including the polycythemia or during a routine examination. It is also found with abdominal pain or flank pain, hematuria, and mass. Some patients complain of fever [13,15].

Metanephric adenoma varies in size, rarely multifocal [11]. This type of tumor is typically demarcated but with no capsule. The surface color varies from gray, brown or 
yellowish. Focal hemorrhagic and necrotic of the tumor are often found, in fact about $20 \%$ of the cases were found with small calcifications and in $10 \%$ of the cases with the formation of cysts [12].

Adenomas are widely ranged, most are 30-60 mm [5]. Bouzourene et al. reported the size of the largest tumour was $20 \mathrm{~cm} \times 19 \mathrm{~cm} \times 15 \mathrm{~cm}[16,17,18]$. In this case, we presented tumour sized $10 \mathrm{~cm} \times 7 \mathrm{~cm} \times 3 \mathrm{~cm}$

Metanephric adenomas are difficult to diagnose through radiological examination. On ultrasound examination, metanephric adenoma shows a demarcated, solid, hyperand hypoechoic mass. However, there were 2 cases of metanephric adenoma with atypical cyst [17].

Doppler examination shows hypovascular lesions. In non-contrast CT examination, metanephric adenoma looks like a well-circumscribed isodense or hyperdense mass compared to the renal parenchyma. [5] The correlation between hyperechoic on ultrasound and hyperdensity on CT scan is the hallmark of benign kidney tumors $[18,19,20]$.

Imaging techniques such as ultrasound and computerized tomography (CT) scan showed demarcated renal lesions [19]. In arteriography, Cases of metanephric adenoma show hypovascularization [20]. In this case, we presented hypoechoic abdominal ultrasound image of the left kidney and hyperdensity in CT- urography obtained at the lower pole of kidney

Metanephric adenoma is a tumor that is highly cellular with a small round, dense uniform acini with an embryonal appearance. Because of acinus and a small hole, sometimes we make a mistake on lower magnification about the pattern, and it is regarded as a solid sheet of cells. Stroma varies from striking up into the loose stroma. Hyalinized scar and focal osseous metaplastic stroma present in $10-20 \%$ of tumors. Approximately 50\% of tumors contain papillary structures, typically consisting of a small cyst protruded as immature glomeruli. There are occasionally a lot of psammoma bodies. Junction with the kidney is usually sharp and without pseudo-capsule. Metanephric adenoma cells are typically monotonous, with a small homogeneous core with no or inconspicuous nucleoli. The core is only slightly larger than lymphocytes with round or smooth oval chromatin. It contains a few pale or pink cytoplasm with rare to no mitotic activity [21].

The main Differential diagnoses are variant of papillary renal cell carcinoma (PRCC) and Wilms' tumor. Morphology and immunohistochemistry can usually reveal the difference although it can be obtained simultaneously [22].

Another difference between epithelial Wilms tumor and metanephric adenoma includes the younger age of patients with Wilms' tumor. It is known that $90 \%$ of Wilms' tumor occurs in the child under six years old [10].

Because of the high prevalence of the Renal Cell Carcinoma and difficult to diagnose on radiological examination, metanephric adenoma can be misdiagnosed preoperatively [19]. Therefore, we perform transperitoneal radical nephrectomy as the gold standard for the management. In other cases, Kosugi et al., Imamoto et al., Granter et al. reported performing partial nephrectomy $[23,24,25]$.

In the future, we should consider other options, such us 'wait and see' [4], needle biopsy [23], and partial nephrectomy when a malignant tumor can be excluded.
In almost all cases, metanephric adenoma showed good clinical outcomes $[13,15]$. But the presence of regional lymph node metastases in the 7-year-old child was reported by Renshaw et al. [10]. Our patient has been well and healthy without recurrence after 48 months.

\section{References}

[1] Niazi S, Arshad M, Karim N, Bukhari H. Metanephric adenoma: Case report and review of the literature. Biomedica 2011; 27: 176-9

[2] Yaqoob N, Paryani JP, Kayani N, Rafique MZ, Biyabani R. Metanephric adenoma: a rare benign renal tumor. J Pak Med Assoc 2005; 55 (11); 511-2.

[3] Torricelli FC, Marchini GS, Campos RS, Gil AO. Metanephric adenoma: clinical, imaging and histological findings. Clinics 2011; 66: 359-61.

[4] Sato H, Miyazawa K, Ikeda R, Suzuki K. Metanephric adenoma in a 59-year-old female, a case report. Acta Urology. Jpn 2004; 50: 41-3.

[5] Szuklaski J, Neska-Dlugosz I, Kwiatkowski S, Czesnin J, Paletas A, Marszalek A. Metanephric adenoma of the left kidney in a 59-year-old female. Contempo Oncol (pozn) 2014: 18; 1-2.

[6] Patel RD, Frederick L, Kohler T, Schwartz B. A case of a metanephric adenoma of the kidney, surgically treated with robotassisted laparoscopy partial nephrectomy. Case report in urology 2013.

[7] Sharma PK, Tiwari P, Singh JP, Bera MK. Metanephric adenoma: a case report and review of the literature. Saudi J Kidney Dis Transpl 2013; 24 (5): 1027-30.

[8] Taheri D, Ghasemibasir H, Pooralborzi F, Kabiri M, Mahzoni P, Fesharakizadeh M. Metanephric adenoma of the kidney: case report and review of immunohistochemical staining. Case Rep Clin Pract Rev 2007; 8: 284-8.

[9] Hong M, Liduan Z, Chengkai Z, Qiangsong T. Metanephric adenoma in a 2-year-old child: case report and immunohistochemical observations. J of Pediatric Hematology/oncology 2010; 32: 489-93.

[10] Renshaw AA, Freyer DR, Hammers YA. Metastatic metanephric adenoma in a child. Am J Surg Pathol 2000; 24 (4): 570-4.

[11] Kohashi K, Oda Y, Nakamori M, Yamamoto H, Tamiya S, Toubo $\mathrm{T}$, et al. Multifocal metanephric adenoma in childhood. Pathol Int 2009; 59 (1): 49-52.

[12] Pages A, Granier M. Nephrogenic nephroma. Arch Anat Cytol Pathol 1980; 28: 99-103.

[13] Davis CJ, Barton JH, Sesterhenn IA, Mostofi FK. Metanephric adenoma. Clinicopathological study of fifty patients. Am J Surg Pathol 1995; 19: 1101-4.

[14] Liniger B, Wolf RW, Fleischmann A, Kluwe W. Local resection of metanephric adenoma with kidney preservation. J Paediatr Surg 2009; 44 (8): 21-3.

[15] Jones EC, Pins M, Dickersin GR, Young RH. Metanephric adenoma of the kidney. A clinicopathological, immunohistochemical, flow cytometric, cytogenetic and electron microscopic study of 7 cases. Am J Surg Pathol 1995; 19: 615-26.

[16] Bouzourene H, Blaser A, Francke ML, Chaubert P, Bouzourene N Metanephric adenoma of the kidney: a rare tumor of the kidney. Histopath 1997; 31: 485-6.

[17] Patankar T, Punekar S, Madiwale C, Prasad S, Hanchate V. Metanephric adenoma in a solitary kidney. The Brit J Radiol 1992; 72: 80-1.

[18] Ele JN, Grignon DJ, Moch H. Metanephric adenoma and metanephric adenofibroma. In: The WHO classification of the urinary system and male genital organs. Eble JN, Sauter G, Epstein JI, Sesterhenn IA (eds.). $1^{\text {st }}$ ed. IARC Press, Lyon 2004; Chapter 1: 44-6.

[19] Zhang LJ, Yang GF, Shen W, Lu GM. CT and ultrasound finding of metanephric adenoma: a report of two cases and literature review. The British Journal of Radiology 2011; 84: e51-4.

[20] Yu CH, Lang W, Lin FY, Wei Z, Guang BC. The imaging features of metanephric adenoma: a case report and review of the literature. Onco Targets and Therapy 2015; 8: 445-9. 
[21] Zafar N, Spencer D, Berry AD III. Embryonal adenoma of the kidney: a report of two cases. Diagn Cytopathol 1997; 16: 42-6.

[22] Ban S, Yoshii S, Tsuruta A. Metanephric adenoma of the kidney: ultrastructural, immunohistochemical and lectin histochemical studies. Pathol Int 1996; 46: 661-6.

[23] Kosugi M, Nagata H, Nakajima J. A case of metanephric adenoma treated with partial nephrectomy. Jpn J Urol 2000; 91: 489-92.

[24] Imamoto T, Furuya Y, Ueda T. Metanephric adenoma of the kidney. Int J Urol 1999; 6: 200-2.

[25] Granter SR, Fletcher JA, Renshaw AA. Cytologic and cytogenic analysis of metanephric adenoma of the kidney: a report of two cases. Am J Clin Pathol 1997; 108: 544-9. 